\title{
A revolution in preventing fatal craniovertebral junction injuries: lessons learned from the Head and Neck Support device in professional auto racing
}

\author{
Anand Kaul, BS, ${ }^{1}$ Ahmed Abbas, BS, ${ }^{1}$ Gabriel Smith, MD, ${ }^{1}$ Sunil Manjila, MD, ${ }^{1}$ Jonathan Pace, MD, ${ }^{1}$ \\ and Michael Steinmetz, MD2,3
}

\begin{abstract}
${ }^{1}$ Department of Neurosurgery, University Hospitals, Case Medical Center; ${ }^{2}$ Department of Neurosurgery, Case Western Reserve University, MetroHealth Medical Center; and ${ }^{3}$ Center for Spine Health, Neurologic Institute, Cleveland Clinic, Cleveland, Ohio
\end{abstract}

\begin{abstract}
Fatal craniovertebral junction (CVJ) injuries were the most common cause of death in high-speed motor sports prior to 2001. Following the death of a mutual friend and race car driver, Patrick Jacquemart (1946-1981), biomechanical engineer Dr. Robert Hubbard, along with race car driver and brother-in-law Jim Downing, developed the concept for the Head and Neck Support (HANS) device to prevent flexion-distraction injuries during high-velocity impact. Biomechanical testing showed that neck shear and loading forces experienced during collisions were 3 times the required amount for a catastrophic injury. Crash sled testing with and without the HANS device elucidated reductions in neck tension, neck compression, head acceleration, and chest acceleration experienced by dummies during high-energy crashes. Simultaneously, motor sports accidents such as Dale Earnhardt Sr.'s fatal crash in 2001 galvanized public opinion in favor of serious safety reform. Analysis of Earnhardt's accident demonstrated that his car's velocity parallel to the barrier was more than 150 miles per hour (mph), with deceleration upon impact of roughly $43 \mathrm{mph}$ in a total of 0.08 seconds. After careful review, several major racing series such as the National Association for Stock Car Auto Racing (NASCAR) and Championship Auto Racing Team (CART) made major changes to ensure the safety of drivers at the turn of the 21st century. Since the rule requiring the HANS device in professional auto racing series was put in place, there has not been a single reported case of a fatal CVJ injury.

http://thejns.org/doi/abs/10.3171/2015.10.SPINE15337
\end{abstract}

KEY WORDS ring fracture; Head and Neck Support device; HANS device; automotive racing; craniovertebral junction; trauma

$\mathrm{T}$ 1 HE invention of gasoline-fueled combustion engines in the early 1880 s was soon followed by the first-ever organized automobile racing competition, a 50-mile reliability test in an 1894 race from Paris to Rouen, France. The average speed of the winners of this historic race was just over 10 miles per hour (mph)..$^{5}$ The year 1896 brought the first oval track, a 1-mile irregular dirt track in Cranston, Rhode Island. ${ }^{4}$

\section{High-Speed Auto Racing}

It was not long before the dangers of motor sports became apparent. From 1990 to 2002 alone, 204 drivers died at motor sports events, in addition to 29 spectators, 5 of them children. ${ }^{13}$ In comparison, the Journal of Combative Sport/EJMAS reported a total of 488 boxing-related deaths, with two-thirds due to cranial or cervical injuries, from January 1960 to August $2011 .{ }^{26}$ The high risk of injury in auto racing necessitated the development of novel safety features such as multipoint seat belt restraints, durable helmets, Lexan multilayer windshields, and less flammable fuel, along with softer retaining walls and high fences for the protection of both drivers and spectators in the event of a crash.

There has been a constant coevolution between the enhanced safety of new racing technologies and the nuanced risks they bring. For example, the development of seat belts in race cars was initially met with resistance. Although seat belts prevented race car drivers from being ejected from the car in the event of a crash, these devices were scorned for increasing the potential risk of being trapped inside a flammable crashed vehicle. ${ }^{16}$ The evolution of met-

ABBREVIATIONS AIS = Abbreviated Injury Scale; ATD = Anthropomorphic Testing Device; CART = Championship Auto Racing Team; CVJ = craniovertebral junction; FIA = Fédération Internationale de l'Automobile; GM = General Motors; HANS = Head and Neck Support; IARV = Injury Assessment Reference Value; mph = miles per hour; NASCAR = National Association for Stock Car Auto Racing; SAE = Society of Automotive Engineers; SFI = SFI Foundation, Inc.; TBI = traumatic brain injury. SUBMITTED March 20, 2015. ACCEPTED October 6, 2015.

INCLUDE WHEN CITING Published online July 12, 2016; DOI: 10.3171/2015.10.SPINE15337. 

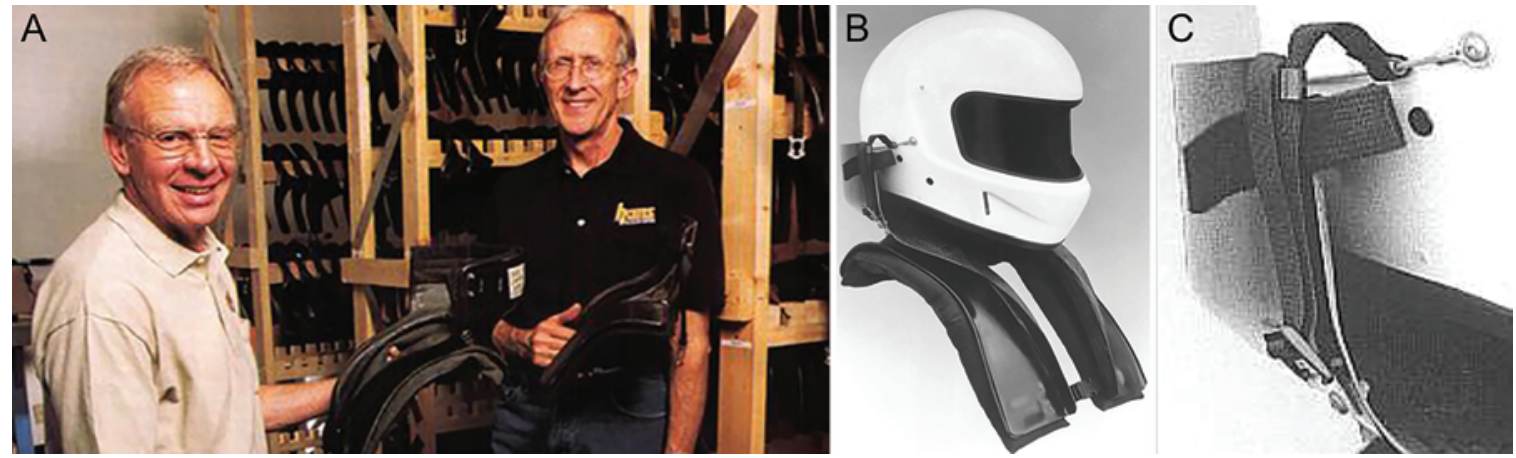

FIG. 1. A: Photograph of the HANS device coinventors: Dr. Robert Hubbard (left) with race car driver and brother-in-law Jim Downing (right). B: The first-generation HANS device (1990). The device was designed to fit over the shoulders of the driver and attach to the helmet to stabilize the CVJ by restricting head motion and dissipating neck loads into the torso. C: Fixed-length and adjustable-length tethers are used to attach the device to the helmet. This allows for some freedom of movement when driving, while still ensuring proper restraint of the head during a collision. Panel A reprinted with permission from "Saving Racing's Neck." Car and Driver, April 2004 (copyright Richard Dole), and panels B and C reprinted with permission from Hubbard RP, Begeman PC, Downing JR: Biomechanical Evaluation and Driver Experience with the Head and Neck Support. SAE Technical Paper, 1994. Figure is available in color online only.

al helmets led to their replacing the predominant cloth or leather helmets by the $1950 \mathrm{~s}$, but despite the added potential benefit of reducing blunt skull trauma, metal helmets also introduced a new set of risks in the potentially lethal flexion-distraction forces at the craniovertebral junction (CVJ). One study investigated helmet weight and the risk of fatal skull base injury in motorcyclists and concluded that the overall risk was $9.2 \%$, and that for riders whose helmets weighed more than $1.5 \mathrm{~kg}$ there was a statistically significant increase in the incidence of these injuries. ${ }^{14}$

\section{The HANS Device}

Dr. Robert Hubbard, a biomechanical engineer at Michigan State University, and his brother-in-law Jim Downing, a race car driver, developed the concept for the Head and Neck Support (HANS) device following the death of a mutual friend and race car driver, Patrick Jacquemart (1946-1981). ${ }^{11}$ Hubbard's extensive career as a biomechanical crash engineer gave him insight into the severity of accelerative forces placed on the CVJ of drivers. The initial prototype of the HANS device was designed to fit elegantly over the driver's shoulders and attach to the helmet, allowing for increased resistance to flexion and distraction vectors during deceleration, deflecting translational head motion into the torso (Fig. 1). ${ }^{11}$ The helmet did not significantly limit the driver's vision, because the driver's head could maintain some lateral and rotational movement due to the use of fixed-length sliding tethers on either side of the helmet.

To study the neck tension loading felt by drivers during crashes, Hubbard et al. used crash sled tests, Anthropomorphic Testing Devices (ATDs), and the injury threshold value guidelines developed by General Motors (GM) (Figs. 2 and 3, and Video 1).11,18,19

VIDEO 1. Crash comparisons using an ATD with and without the HANS device. Courtesy of Dr. Robert Hubbard, the copyright holder. Click here to view.

Predictive thresholds are known for severe CVJ injury, with axial tension exceeding $740 \mathrm{lbs}$ and forward neck shear exceeding $700 \mathrm{lbs} .{ }^{17}$ While conducting sled tests performed with and without the HANS device, Hubbard et al. found a significant reduction in neck loading when the device was used, from $1350 \mathrm{lbs}$ to $296 \mathrm{lbs}$ (Fig. 4). Neck tension and shear forces were found to be 1120 and $750 \mathrm{lbs}$, respectively, without the use of the HANS device. With the use of the HANS device Hubbard et al. found that neck tension and shear were only $210 \mathrm{lbs}$ each, well below the injury threshold. ${ }^{11}$ These authors also examined dif-

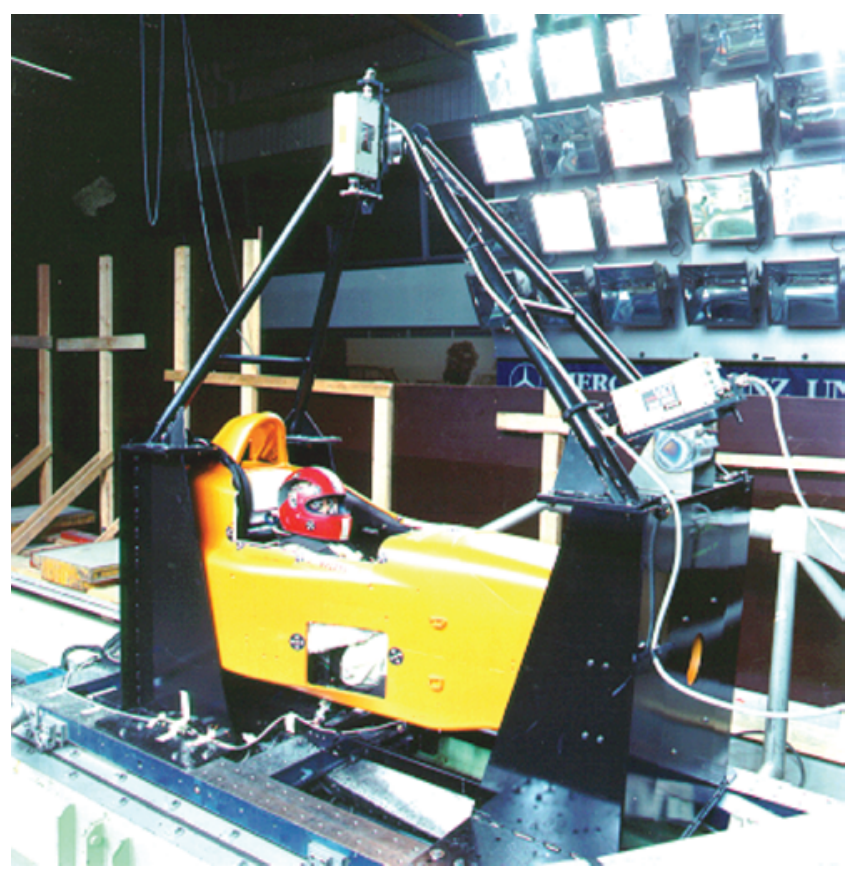

FIG. 2. Crash test sled used by Mercedes Benz. Crash test dummies are placed in ATDs that can be used to simulate loads on a driver under various collision conditions. The ATD can be set up to model different driving positions, impact angles, and crash velocities. Cameras can be seen mounted around the ATD to record the motion of the dummy during the collision testing. Photograph courtesy of Dr. Robert Hubbard. Figure is available in color online only. 

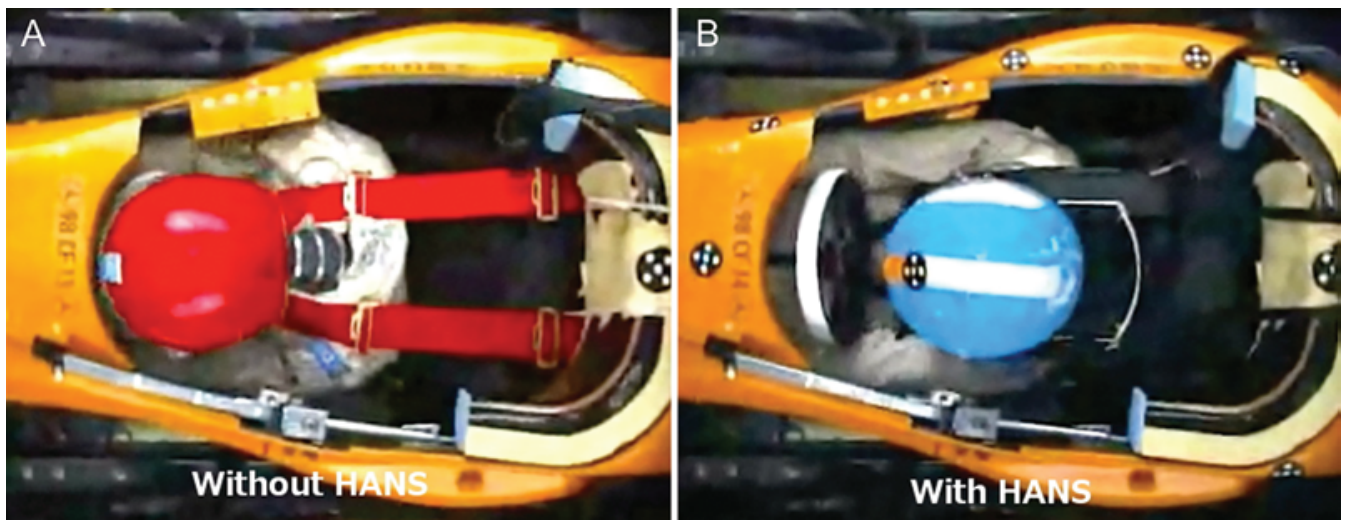

FIG. 3. Comparison using an ATD with and without the HANS device. The results of a simulated head-on crash at 40 mph using the Mercedes Benz ATD simulation. A: Without the HANS device, a large amount of neck tension is exhibited on the test dummy. B: With the HANS device, the neck and head are kept closer to the torso by distributing loads across the shoulders and chest of the driver. Photograph courtesy of Dr. Robert Hubbard. Figure is available in color online only.

ferential positioning of the HANS device to investigate its efficacy across different styles of auto racing, such as the more reclined $\left(45^{\circ}\right)$ position used by IndyCar and Formula 1 drivers and the upright $\left(30^{\circ}\right)$ position used in NASCAR. The HANS device significantly reduced tension and shear forces on the neck in both seating positions (Table 1).

In 2002, Gideon et al. also investigated the effects of variable crash deceleration time histories on resultant neck tension during automobile crashes with and without the use of the HANS device. ${ }^{6}$ To simulate a life-threatening crash energy level, all trials used a 40 -mph crash velocity at a $36^{\circ}$ right front angle barrier impact. The forces measured on the ATDs during crash testing included neck tension and compression, head acceleration, and chest ac- celeration; Injury Assessment Reference Values (IARVs) were used to judge injury potential associated with dummy measurements. The HANS device was found to effectively reduce the neck tension to less than $225 \mathrm{lbs}$ of force, well below the IARV criterion of $900 \mathrm{lbs}$ used to assess injury for all types of deceleration time histories. These studies provided validation for the effectiveness of the HANS device, showing an $80 \%$ reduction in flexiondistraction force on the head and neck compared with controls (Table 1). Following the death of Formula 1 driver Aryton Senna in 1994, DaimlerChrysler investigated sled testing with the HANS device, concluding that the device was both efficacious and safe. ${ }^{7-9}$ With the cooperation of DaimlerChrysler, the second-generation HANS device

\section{Without HANS}
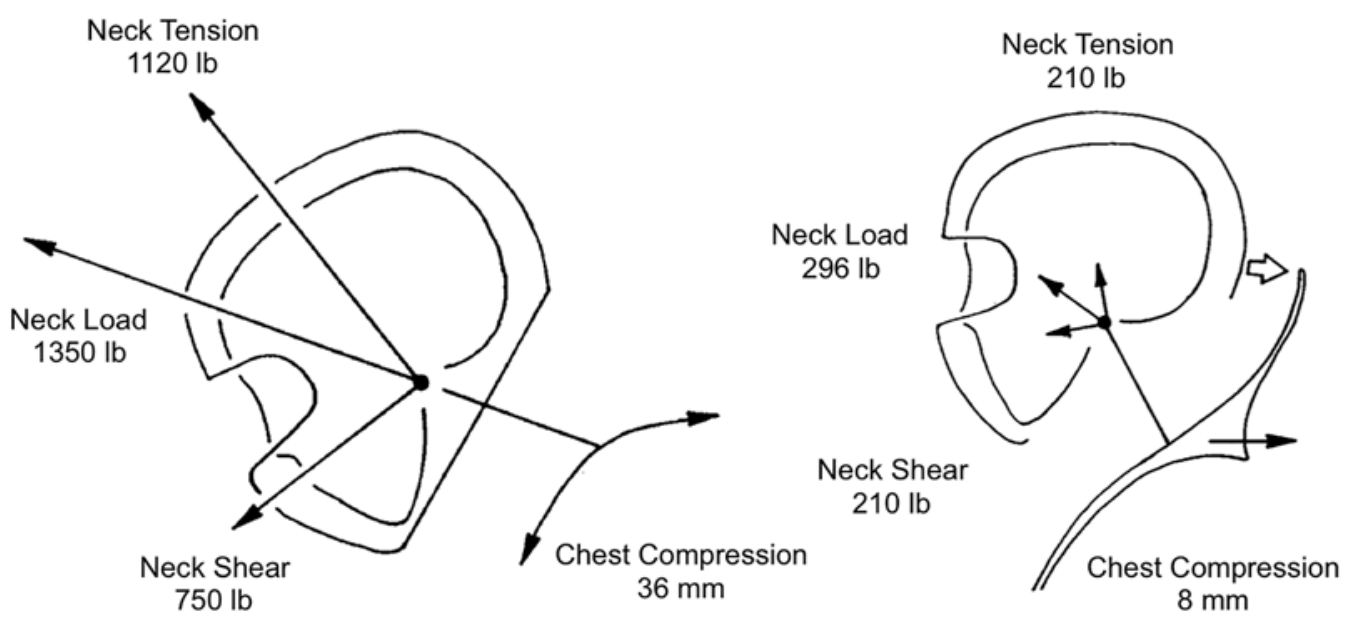

FIG. 4. Force diagrams demonstrating typical results from frontal crash test with and without HANS. The guidelines as developed by GM and the SAE indicate that the threshold values to prevent head and neck injury should not exceed $740 \mathrm{lbs}$ axial neck tension, $700 \mathrm{lbs}$ forward shear, and $900 \mathrm{lbs}$ compression, and that chest compression should not exceed $51 \mathrm{~mm}$ (Hubbard et al.). This testing was conducted by GM to simulate a $45-\mathrm{mph}$ crash at a $45^{\circ}$ seat back angle to model the reclined position as seen in IndyCar and Formula 1 racing. Without the HANS device, the neck load values all exceed the injury thresholds, with neck axial tension and shear at $1122 \mathrm{lbs}$ and $752 \mathrm{lbs}$, respectively. With the HANS device all load values are significantly below thresholds, with neck axial tension and shear at $210 \mathrm{lbs}$ and axial compression at $290 \mathrm{lbs}$. Reprinted with permission from Hubbard RP, Begeman PC, Downing JR: Biomechanical Evaluation and Driver Experience with the Head and Neck Support. SAE Technical Paper, 1994. 
TABLE 1. Testing data results from the frontal impact crash sled testing of the HANS device as conducted by GM*

\begin{tabular}{lccccc}
\hline Neck Support Condition & $\begin{array}{c}\text { Sled Velocity Change, } \\
\text { Seat Back Angle }\end{array}$ & $\begin{array}{c}\text { Neck Forward } \\
\text { Shear Load (lbs) }\end{array}$ & $\begin{array}{c}\text { Neck Axial } \\
\text { Load (lbs) }\end{array}$ & $\begin{array}{c}\text { Total Neck Stretch } \\
\text { Load (lbs) }\end{array}$ & $\begin{array}{c}\text { Chest } \\
\text { Compression (mm) }\end{array}$ \\
\hline Tolerance thresholdst & & 698 & $765-900 \ddagger$ & 698 & 51 \\
\hline No neck support & $45 \mathrm{mph}, 30^{\circ}$ seat & 617 & 806 & 1011 & 1352 \\
& $45 \mathrm{mph}, 45^{\circ}$ seat & 752 & 1122 & 151 & 25 \\
\hline With neck support & $45 \mathrm{mph}, 30^{\circ}$ seat & 151 & $0-270$ & 296 & 8 \\
\cline { 2 - 6 } & $45 \mathrm{mph}, 45^{\circ}$ seat & 210 & $210-290$ & 25 \\
\hline
\end{tabular}

\begin{abstract}
* Front-impact tests were performed using the ATD and conducted at $45 \mathrm{mph}$ at $30^{\circ}$ and $45^{\circ}$ seat angles, designed to model Formula 1 seating positions. The tests were performed both with and without the HANS device, with loads measured. Modified with permission from Hubbard RP, Begeman PC, Downing JR: Biomechanical Evaluation and Driver Experience with the Head and Neck Support. SAE Technical Paper, 1994.

$\dagger$ Tolerance threshold values as determined by GM and the SAE for maximum allowed loads to prevent injury to the head and neck.

$\ddagger$ Axial loads are measured as extension (positive) and compression (negative). Extension loads are indicative of distractive injuries. Compression loads are caused by the head pushing down on the neck due to the restraint provided by the HANS device.
\end{abstract}

was created. The adoption rate for the HANS device by race car drivers remained poor, however, because even with research and testing indicating their potential safety benefit, marketing and awareness of these devices lagged behind for nearly 5 years. ${ }^{25,27}$ This delay continued until 2001 when, during his final lap of the Daytona 500, Dale Earnhardt Sr. was involved in a fatal collision. Root-cause analysis of his death determined that his car decelerated so rapidly that he suffered a fatal CVJ injury.

The passing of Earnhardt was one of the most tragic events in modern motor sports. His fatal crash on February 18, 2001, was extensively investigated. Earnhardt's No. 3 car was making the fourth turn of his last lap when his left rear bumper made contact with the No. 40 car, causing him to yaw counterclockwise toward the center of the track. A corrective sharp turn back to the right sent him up the racing surface into the path of the No. 36 car, which made unavoidable impact with Earnhardt's passenger door area just before he made angled contact with the side wall.

Analyses of the crash component velocity vectors demonstrated that Earnhardt's car had an impact velocity in excess of $150 \mathrm{mph}$ and experienced a total deceleration of 43-44 mph in a period of 0.08 seconds, with the equivalent forces of $45-50 \mathrm{~g}^{22}$ Injury causation analysis likened the velocity change due to the crash to that of a parked car being struck head on by a similar car traveling $75 \mathrm{mph}^{3}$ The final cause of death was found to be a fatal CVJ injury with an associated basilar ring fracture; however, the mechanism of fracture was heavily debated. The official NASCAR crash report explained that impact to the occipital scalp in conjunction with the tension and torsion stress to the base of the skull resulted in the fracture, and additional consultation by Dr. Barry Myers described a "whip" mechanism resulting from the differential restraint of the torso and head, leading to a lethal flexion-distraction injury. ${ }^{22}$

Earnhardt's crash marked a turning point for the adoption of head and neck restraint systems, with NASCAR mandating the use of these restraint systems in cars in 2001. The creation of the head and neck restraint specifications by auto racing's nonprofit quality assurance company, the SFI Foundation, Inc. (SFI) (specification 38.1; www.sfifoundation.com/wp-content/pdfs/specs/ Spec_38.1_031615.pdf), should have heralded the arrival of many new neck restraint devices. However, by 2004 only 2 of these were certified, including the long-standing HANS device. The Fédération Internationale de l'Automobile (FIA) mandated the use of the third-generation HANS device for Formula 1 racing in 2003 (Fig. 5). By 2007, more than 40 sanctioning bodies required the use of SFI-certified devices. ${ }^{25}$
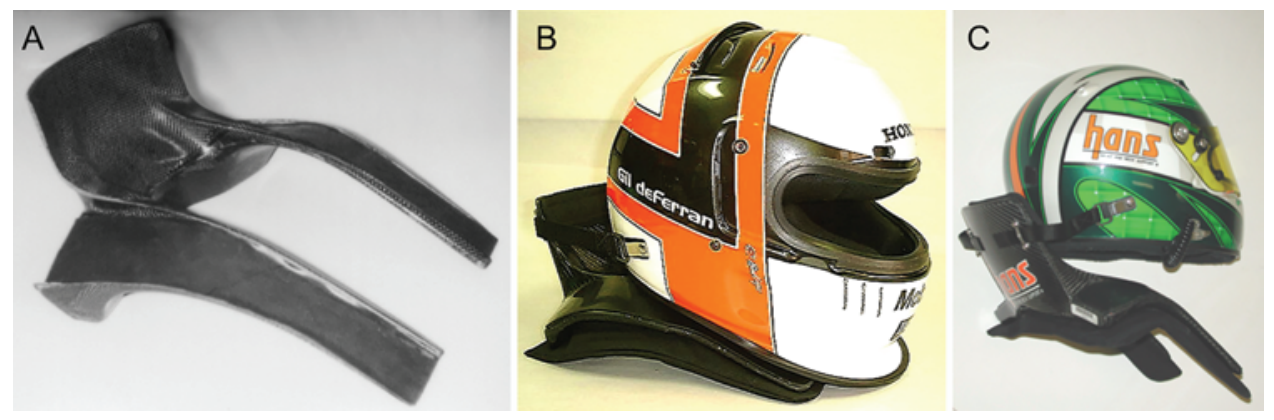

FIG. 5. More recent HANS devices. A: The third-generation HANS device is now fully composite. The device is lighter in weight and significantly less bulky. The device can now be readily modified to meet the individual specifications for drivers as well as the general requirements for a different racing series (regarding positioning of the helmet in relation to the device). B: The HANS device as used in CART racing required a more reclined position. C: The HANS device as used in NASCAR required a more upright driving position. Photographs courtesy of Dr. Robert Hubbard. Figure is available in color online only. 
According to clinical literature, basilar skull ring fractures occur from distraction or compressive forces. ${ }^{15,28}$ Compression ring fractures occur from a vertical fall from a height or direct impact to the top of the head and are often associated with fatal downward displacement of the posterior fossa, brainstem, and vascular structures. Flexion-distraction ring fractures and atlantooccipital dislocation occur when forces applied to the head are sufficient to cause suture diastasis during acceleration experienced by the head and torso, which is often fatal as well., $1,2,12,23,31$ Pollanen et al. evaluated a series of 8 fatal basilar skull fractures and found that fractures of the petrous portion of temporal bones will often involve laceration of the internal carotid arteries, leading to massive hemorrhage. ${ }^{21}$ These fractures can involve the middle ear as well and create a carotid-middle ear fistula leading to rapid exsanguination..$^{21,30}$

The grave prognosis of these high-velocity sports injuries from atlantooccipital dissociation, fatal vascular injuries, and concurrent basilar skull ring fractures necessitated further investigation into prevention and safety. Trammell and Hubbard explored medical and technical outcomes of the HANS device in Championship Auto Racing Team (CART) series racing. ${ }^{27}$ They found that in 2000 and 2001, there were 28 incidents involving 33 drivers using the HANS device, with 0 fatalities, 0 cervical fractures or dislocations, 1 minor head injury, and 8 drivers with minor neck complaints. ${ }^{27}$ In comparison, between 1985 and 1999 there were a total of 146 different injuries to drivers, 11 of which $(7.5 \%)$ involved the cervical spine, resulting in 2 fatalities. ${ }^{20}$ Trammell and Hubbard compared 2 crashes experienced by a single driver-one in which the HANS device was implemented and another in which it was not. The crash in which the HANS device had been used had a higher rear-impact acceleration $(100 \mathrm{~g}$ vs $66 \mathrm{~g}$ ) and a velocity change from 44 to $22 \mathrm{mph}$, but the driver sustained a lower-grade concussion without any neck symptoms or soft-tissue injury.

Traumatic brain injury (TBI) is another major source of death from trauma. Studies using Indy Racing League (IRL) data showed a dramatic increase in risk of TBI with collision accelerations in excess of 50g. ${ }^{29}$ An analysis of NASCAR data showed that increased head acceleration provided a good correlation with injury severity according to the Abbreviated Injury Scale (AIS), ranging from loss of consciousness to hemorrhage to fatal skull fracture. ${ }^{24}$ These studies have not directly examined the benefits of the HANS device, but it may be interesting to investigate what effect the reduced loads on the head and neck of the driver would have on the overall AIS severity.

In the US alone, 42,000 traffic fatalities and 6.1 million traffic accidents occur each year. Meanwhile, NASCAR drivers averaged 220 crashes per year over 9 years from 2001 to 2009. Based on this ratio, there should have been 15 deaths since 2001; however, there have been none reported. ${ }^{10}$

\section{Conclusions}

The HANS device, with an $80 \%$ reduction in flexiondistraction vectors, has led to dramatic declines in fatal
CVJ injuries. Critical understanding of the biomechanical forces at the CVJ led to the invention of the HANS and other similar CVJ-stabilizing devices, revolutionizing safety in high-speed racing. Initial adoption of HANS devices was low due to a lack of community awareness of the injuries involved. The tragic death of Dale Earnhardt Sr. had a lasting cultural impact on auto racing because it was a turning point for the adoption of HANS devices. Since requirements mandating the use of head and neck support devices were put in place in 2001, there have been no reported fatalities due to $\mathrm{CVJ}$ injuries.

\section{Acknowledgments}

This study was done as a retrospective review of neurosurgical and Society of Automotive Engineers (SAE) literature. We thank NASCAR, CART, SAE, Dr. Robert Hubbard, Mr. Tom Gideon, Dr. Stephen Olvey, Dr. Terry Trammell, Dr. John Hopkins, and all of their associates for vital contributions to the manuscript. Crash sled test data were provided by Dr. Robert Hubbard and Mr. Tom Gideon.

\section{References}

1. Adams VI: Neck injuries: I. Occipitoatlantal dislocation-a pathologic study of twelve traffic fatalities. J Forensic Sci 37:556-564, 1992

2. Adams VI: Neck injuries: II. Atlantoaxial dislocationa pathologic study of 14 traffic fatalities. J Forensic Sci 37:565-573, 1992

3. Benedict JV, Raddin JH: Injury causation analysis of 18 February 2001 race car accident involving the No. 3 car, in Official Accident Report, No. 3 Car. Daytona Beach, FL: NASCAR Publications, 2001

4. Brown AE: The History of America's Speedways: Past and Present. Comstock Park, MI: America's Speedways, 2003

5. Fink JJ: The Automobile Age. Cambridge, MA: MIT Press, 1990

6. Gideon T, Melvin J, Streetz L, Willhite S: ATD Neck and Tension Comparisons for Various Sled Pulses. SAE Technical Paper 2002-01-3324. Warrendale, PA: SAE International, 2002

7. Gramling H, Hodgman P, Hubbard R: Development of the HANS Head and Neck Support for Formula One. SAE Technical Paper 983060. Warrendale, PA: SAE International, 1998

8. Gramling H, Hubbard R: Development of an Airbag System for FIA Formula One and Comparison to the Hans Head and Neck Support. SAE Technical Paper 2000-013543. Warrendale, PA: SAE International, 2000

9. Gramling H, Hubbard R: Sensitivity Analysis of the HANS Head and Neck Support. SAE Technical Paper 2000-013541. Warrendale, PA: SAE International, 2000

10. Hill M: NASCAR Safety Improvements Save Lives. Chesterfield, MO: Reinsurance Group of America, Inc., 2012

11. Hubbard RP, Begeman PC, Downing JR: Biomechanical Evaluation and Driver Experience with the Head and Neck Support. SAE Technical Paper 942466. Warrendale, PA: SAE International, 1994

12. Imaizumi $\mathrm{T}$, Sohma $\mathrm{T}$, Hotta $\mathrm{H}$, Teto I, Imaizumi H, Kaneko $\mathrm{M}$ : Associated injuries and mechanism of atlanto-occipital dislocation caused by trauma. Neurol Med Chir (Tokyo) 35:385-391, 1995

13. Jenkins JR: Not necessarily the best seat in the house: a comment on the assumption of risk by spectators at major auto racing events. Tulsa Law J 35:163-191, 1999 
14. Konrad CJ, Fieber TS, Schuepfer GK, Gerber HR: Are fractures of the base of the skull influenced by the mass of the protective helmet? A retrospective study in fatally injured motorcyclists. J Trauma 41:854-858, 1996

15. Le Count ER, Hockzema J: Symmetrical traumatic fractures of the cranium; symmetrical fragmentation. Arch Surg 29:171-226, 1934

16. Majerus JN: Winning More Safely in Motorsports: The Workbook. Middletown, DE: Racing Vehicles, Inc., 1999

17. Melvin J: Human tolerance to impact conditions as related to motor vehicle design. SAE Standard J885. Warrendale, PA: SAE International, 1980

18. Melvin JW, Little WC, Jedrzejczak EA, Pierce J: Racing Car Restraint System Frontal Crash Performance Testing. SAE Technical Paper 942482. Warrendale, PA: SAE International, 1994

19. Mertz HJ: Anthropomorphic test devices, in Nahum AM, Melvin JW (eds): Accidental Injury: Biomechanics and Prevention. New York: Springer, 2002, pp 72-88

20. Olvey S: Rapid Response: My Inside Story as a Motor Racing Life-Saver. Somerset, UK: Haynes Publishing, 2006

21. Pollanen MS, Deck JH, Blenkinsop B, Farkas EM: Fracture of temporal bone with exsanguination: pathology and mechanism. Can J Neurol Sci 19:196-200, 1992

22. Sicking DL: Accident reconstruction of No. 3 Car Crash at Daytona 500, in Official Accident Report, No. 3 Car. Daytona Beach, FL: NASCAR Publications, 2001

23. Simpson DA, Blumbergs PC, Cooter RD, Kilminster M, McLean AJ, Scott G: Pontomedullary tears and other gross brainstem injuries after vehicular accidents. J Trauma 29:1519-1525, 1989

24. Somers JT, Granderson B, Melvin JW, Tabiei A, Lawrence C, Feiveson A, et al: Development of head injury assessment reference values based on NASA injury modeling. Stapp Car Crash J 55:49-74, 2011

25. Stiles M, Walker A, Milgrom G: HANS Device-Performance Leader to Market Leader. SAE Technical Paper Series 2006-01-3629. Warrendale, PA: SAE International, 2006

26. Svinth JR: Death under the spotlight: the Manuel Velazquez boxing fatality collection. Journal of Combative Sport/
EJMAS. November 2007. (http://ejmas.com/jcs/jcsart svinth_a_0700.htm) [Accessed March 21, 2016]

27. Trammell TR, Hubbard RP: Medical and Technical Outcomes of HANS Use in CART. SAE Technical Paper Series 2002-01-3350. Warrendale, PA: SAE International, 2002

28. Vance BM: Fractures of the skull: complications and causes of death: a review of 512 necropsies and of 61 cases studied clinically. Arch Surg 14:1023-1092, 1927

29. Weaver CS, Sloan BK, Brizendine EJ, Bock H: An analysis of maximum vehicle $\mathrm{G}$ forces and brain injury in motorsports crashes. Med Sci Sports Exerc 38:246-249, 2006

30. Zakrzewski A, Konopacki K, Kwaskowski A, Gradzki J: [Rupture of the internal carotid artery during fracture of the cranial base.] Otolaryngol Pol 23:685-692, 1969 (Polish)

31. Zhu BL, Quan L, Ishida K, Taniguchi M, Oritani S, Fujita $\mathrm{MQ}$, et al: Longitudinal brainstem laceration associated with complex basilar skull fractures due to a fall: an autopsy case. Forensic Sci Int 126:40-42, 2002

\section{Disclosures}

Dr. Steinmetz is a consultant for Stryker Spine, Biomet, DePuy Synthes, and Intellirod. He also receives royalties from Biomet.

\section{Author Contributions}

Conception and design: all authors. Acquisition of data: Smith, Kaul, Abbas. Analysis and interpretation of data: Smith, Kaul, Abbas, Steinmetz. Drafting the article: Smith, Kaul, Abbas, Steinmetz.

\section{Supplemental Information \\ Videos \\ Video 1. https://vimeo.com/159214496.}

\section{Correspondence}

Gabriel Smith, Department of Neurosurgery, University Hospitals, Case Medical Center, 11100 Euclid Ave., Hanna House 5th Fl., Cleveland, OH 44106. email: gabriel.smith@uhhospitals.org. 